\title{
openheart Development of heart failure in young patients with congenital heart disease: a nation-wide cohort study
}

\author{
Thomas Gilljam, ${ }^{1,2}$ Zacharias Mandalenakis, ${ }^{1,2}$ Mikael Dellborg, ${ }^{1,2}$ \\ Georgios Lappas, ${ }^{1}$ Peter Eriksson, ${ }^{1,2}$ Kristofer Skoglund, ${ }^{1}$ Annika Rosengren ${ }^{1}$
}

\begin{abstract}
- Additional material is published online only. To view please visit the journal online (http://dx.doi.org/10.1136/ openhrt-2018-000858).
\end{abstract}

To cite: Gilljam T, Mandalenakis Z, Dellborg M, et al. Development of heart failure in young patients with congenital heart disease: a nation-wide cohort study. Open Heart 2019;6:e000858. doi:10.1136/ openhrt-2018-000858

\section{TG and ZM contributed equally.}

Received 18 May 2018 Revised 13 December 2018 Accepted 10 February 2019

Check for updates

\section{Author(s) (or their} employer(s)) 2019. Re-use permitted under CC BY-NC. No commercial re-use. See rights and permissions. Published by BMJ.

${ }^{1}$ Department of Molecular and Clinical Medicine, Goteborgs universitet Sahlgrenska Akademin, Goteborg, Sweden ${ }^{2}$ Department of Internal Medicine, Sahlgrenska University Hospital, Ostra, Goteborg, Sweden

Correspondence to Dr Zacharias Mandalenakis; zacharias.mandalenakis@ vgregion.se

\section{ABSTRACT}

Objective Heart failure (HF) is a common cause of hospitalisation and death in adults with congenital heart disease (CHD). However, the risk of HF in young patients with $\mathrm{CHD}$ has not been determined.

Methods By linkage of national patient registers in Sweden, we identified 21982 patients with CHD born between 1970 and 1993, and compared these with 10 controls per case. Follow-up data were collected from birth until 2011 or death.

Results Over a mean follow-up of 26.6 years in patients with CHD and 28.5 years in controls, 729 (3.3\%) and $75(0.03 \%)$ developed HF, respectively. The cumulative incidence of $\mathrm{HF}$ in all $\mathrm{CHD}$ was $6.5 \%$ and in complex CHD $14.8 \%$ up to age 42 years. Thus, one patient in 15 with $\mathrm{CHD}$ runs the risk of developing HF before age 42 years, a risk that is 105.7 times higher $(95 \% \mathrm{Cl} 83.2$ to 134.8) compared with controls. For patients with complex CHD (such as conotruncal defects, univentricular hearts, endocardial cushion defects), one in seven will develop HF, a HR of $401.5 ; 95 \% \mathrm{Cl} 298$ to 601 as compared with controls. The cumulative probability of death in patients with $\mathrm{CHD}$, after HF diagnosis, was $63.4 \%(95 \% \mathrm{Cl} 57.5$ to 69.3).

Conclusions An extremely high risk of developing HF (more than 100-fold) was found in patients with $\mathrm{CHD}$, compared with matched controls, up to the age of 42 years. Patients with complex congenital heart malformations carried the highest risk and have to be considered as the main risk group for developing HF.

\section{INTRODUCTION}

Congenital heart disease (CHD) is the most common potentially fatal malformation of the heart, with an estimated prevalence of 5-10 per 1000 live births. ${ }^{1}$ Major advances in cardiothoracic surgery and cardiac care for patients with CHD during the last five decades have resulted in an increasing population of adults with CHD. ${ }^{1-4}$ The adult population with CHD presents new challenges for healthcare, as many patients are prone to residua and sequelae. ${ }^{5}$

Heart failure (HF) has recently been identified as a major cause of hospital admissions and the most common cause of mortality

\section{Key questions}

What is already known about this subject?

- The survivorship in patients with congenital heart disease (CHD) has been increased over the last decades with improvement in paediatric care and surgical techniques and nowadays more than $90 \%$ reach adulthood. Although patients with CHD are presumed to be at risk for developing acquired cardiovascular diseases such as heart failure (HF).

What does this study add?

- We found that the risk of developing HF was extremely higher (>100 times) in patients with CHD than matched controls, up to the age of 42 years The highest risk $(\mathrm{HR}>300)$ was observed among patients with complex congenital defects, of whom almost $15 \%$ developed HF. Patients with complex congenital defects and HF had $63 \%$ risk of death compared with $11 \%$ in patients with CHD without HF.

How might this impact on clinical practice?

- Prognosis for patients with CHD has greatly improved during the last decade. Despite this, significant morbidity and complications late in life remain frequent and problematic. For the general cardiologist, the general practitioner, the anaesthesiologist, it is of great importance to see the young patient with a corrected congenital heart condition as palliated, not cured and as a patients with significant risk of HF, despite his or her youth and satisfactory childhood surgery.

in adult patients with CHD, accounting for $25 \%-30 \%$ of all deaths and $45 \%$ of cardiovascular deaths. $^{5-9}$

The aim of this study is to determine the risk of developing HF in young patients with CHD, using a national Swedish cohort of patients with CHD and matched controls.

\section{METHODS}

\section{Study population}

We included all patients in the Swedish population with a diagnosis of any type of CHD, 
born between 1 January 1970 and 31 December 1993, and registered at any time from 1970, 2001 and 1970, respectively, on any one of three national databases: the National Hospital Inpatient Register, the Outpatient Register and the National Cause of Death Registers in Sweden, until the end of follow-up on 31 December 2011, as previously described. ${ }^{10}{ }^{11}$ The National Hospital Inpatient Register has complete coverage since 1987, and coverage of all hospitals performing thoracic surgery from 1970. The Outpatient Register includes data from 2001, and the National Cause of Death Registers includes data from 1967. During the study period, there was a successive decrease in the age at which CHD was reported to the registry, from a median age of 6.0 years in the $1970 \mathrm{~s}$ to 1.2 years in the $1990 \mathrm{~s}$.

Diagnoses were coded according to the International Statistical Classification of Diseases and related Health Problems (ICD 8th, 9th and 10th editions) currently in use (online supplementary table 1). Cardiovascular surgical procedures were classified as codes 30-32 (Swedish 6th version of Classification of Operations) or F

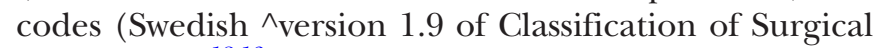
Procedures)..$^{1213}$

The CHD diagnoses were further classified according to a hierarchical system proposed by Botto, ${ }^{14}$ used by Oyen ${ }^{15}$ and recently modified by $\mathrm{Liu}^{16}$ as follows. Group 1 was defined as patients with conotruncal defects, such as common arterial trunk, transposition of the great arteries, tetralogy of Fallot and aortopulmonary septum defect. Group 2 was defined as patients with nonconotruncal defects, such as endocardial cushion defects, common ventricle and hypoplastic left heart syndrome. Group 3 was defined as patients with coarctation of the aorta. Group 4 was defined as patients with ventricular septal defects. Group 5 was defined as patients with atrial septal defects. Group 6 included patients with all other congenital heart defects not included in the other five lesion groups.

Each patient with CHD was matched at birth by birth year, sex, and country, with 10 control individuals without any record of CHD, obtained from the Swedish Total Population Register. Only nine controls were available for four patients with CHD.

\section{Definitions}

A large proportion of patients with HF had CHD as a primary diagnosis; therefore, the first HF diagnosis code in any position was accepted. We defined HF by 427.0 and 427.10 for ICD-8, 428 for ICD-9 and I50 for ICD-10. Hypertension was defined by codes 401-405 (ICD-8 and ICD-9) or I10-I15 (ICD-10), atrial fibrillation by codes 427.92 (ICD-8), 427D (ICD-9) or I48 (ICD-10), diabetes mellitus by codes 250 (ICD-8 and ICD-9) or E10-14 (ICD10 ), stroke by codes 430-432, 434, 436 (ICD- 8 and ICD-9) or I60-I64 (ICD-10) and ischaemic heart disease by codes 410-414 (ICD-8 and ICD-9) or I20-I25 (ICD-10).

Follow-up data for cases and controls were collected at inclusion in the study (first registration of CHD diagnosis) ending on 31 December 2011, or death. Data are presented for men and women and across birth periods as well as CHD severity groups. A HF diagnosis in the Swedish National Inpatient Register has shown a 96\% accuracy for $\mathrm{HF}$ as a primary diagnosis and $86 \%-91 \%$ accuracy for a secondary diagnosis of $\mathrm{HF}^{17}$

The study was approved by the Gothenburg Regional Research Ethics Board. All national registration numbers were replaced with a code in the final dataset by the Swedish National Board of Health and Welfare.

\section{Statistical analysis}

Descriptive statistics were used for demographic data in the study population. Patients were entered into the study at date of birth, regardless of age at CHD diagnosis. HRs with 95\% CI for the development of HF in patients and controls were estimated using a stratified Cox regression model while controlling for age and sex. The HF risk is also presented as incidence rate per $10^{5}$ patient years, compared with controls. Kaplan-Meier estimates were used to calculate cumulative probability of developing HF in patients and controls, as well as cumulative mortality in patients with CHD with HF, compared with patients with CHD without HF.

Two-sided $p$ values were used, and a $p$ value $<0.05$ was considered statistically significant. SAS software (V.9.4; SAS Institute, Cary, NC, USA) and R-software (V.3.1; R Foundation for Statistical Computing, Vienna, Austria) were used to perform the statistical analyses.

\section{RESULTS}

In this study, 21982 patients with a diagnosis of CHD were included and compared with 219816 matched controls. The characteristics of the study population are shown in table 1. Up to 42 years of age, 8352 patients with CHD $(38.0 \%)$ underwent at least one surgical procedure, of which $245(2.9 \%)$ died within 30 days postsurgery.

In total, 729 patients with CHD $(3.3 \%$, median follow-up 27.5 years $)$ and 75 controls $(0.03 \%$, median follow-up 26.2 years) developed HF (table 2). The risk for HF in patients with CHD was 105.7 times higher (95\% CI 83.2 to 134.8), compared with controls. The highest HF risk was identified in the cohort born in the 1980s (HR, 143.4;

Table 1 Baseline characteristics of the study population

\begin{tabular}{lcc}
\hline Characteristic & Patients & \multicolumn{1}{c}{ Controls } \\
\hline All, $\mathrm{n}$ & 21982 & 219816 \\
\hline Men, $\mathrm{n}(\%)$ & $11332(51.6)$ & $113319(51.6)$ \\
\hline 1970s cohort, $\mathrm{n}(\%)$ & $7535(34.3)$ & $75350(34.3)$ \\
\hline 1980s cohort, $\mathrm{n}(\%)$ & $9126(41.5)$ & $91266(41.5)$ \\
\hline 1990s cohort, $\mathrm{n}(\%)$ & $5321(24.2)$ & $53200(24.2)$ \\
\hline Born in Sweden, \% & 91.6 & 92 \\
\hline Mean follow-up age, years & 26.6 & 28.5 \\
\hline Median follow-up age, years & 26.2 & 27.5 \\
\hline
\end{tabular}


Table 2 Risk of HF in patients with CHD compared with matched controls, by sex and birth period

\begin{tabular}{|c|c|c|c|}
\hline Characteristic & $\begin{array}{l}\text { Patients } \\
\text { with CHD } \\
\text { and HF }\end{array}$ & $\begin{array}{l}\text { Controls } \\
\text { with HF }\end{array}$ & HR (95\% Cl) \\
\hline All, n (\%) & $729(3.3 \%)$ & $75(0.03 \%)$ & 105.7 (83.2 to 134.8$)$ \\
\hline Men, n (\%) & $375(3.3 \%)$ & $42(0.04 \%)$ & 95.8 (69.6 to 131.8$)$ \\
\hline Women, n (\%) & $354(3.3 \%)$ & $33(0.03 \%)$ & 118.8 (82.7 to 170.5$)$ \\
\hline $\begin{array}{l}\text { 1970s cohort, } n \\
(\%)\end{array}$ & $383(5.1 \%)$ & $47(0.06 \%)$ & 90.6 (66.7 to 123.0$)$ \\
\hline $\begin{array}{l}\text { 1980s cohort, n } \\
(\%)\end{array}$ & $325(3.6 \%)$ & $24(0.02 \%)$ & 143.4 (94.7 to 217.1) \\
\hline $\begin{array}{l}\text { 1990s cohort, } n \\
(\%)\end{array}$ & $21(0.4 \%)$ & $4(0.008 \%)$ & 53.5 (18.4 to 155.9) \\
\hline
\end{tabular}

$\mathrm{CHD}$, congenital heart disease; HF, heart failure.

95\% CI 94.7 to 217.1). The risk of developing HF in men and women with CHD was high, but there was no significant difference between sexes, HR 95.8 (95\% CI 69.6 to 131.8 ) and 118.8 (95\% CI 82.7 to 170.5 ), respectively.

The HF incidence rate was 124.8 per $10^{5}$ person years (95\% CI 115.8 to 133.9 ) in patients with CHD and 1.2 (95\% CI 0.9 to 1.5 ) in controls (table 3 ). Among complex CHD cases (lesion groups 1 and 2), the incidence rate was $>300$. For complex CHD cases, the HF risk was 401.5 times higher (95\% CI 298 to 601) than that of controls and significantly increased in all lesion groups. A total of 56 patients with CHD were heart transplanted including

\begin{tabular}{|c|c|c|c|c|}
\hline $\begin{array}{l}\text { Lesion } \\
\text { group }\end{array}$ & HF/total & $(\%)$ & $\begin{array}{l}\text { IR/10 } \\
\text { years* }\end{array}$ & $95 \% \mathrm{Cl}$ \\
\hline Group 1 & $157 / 2,022$ & -7.8 & 348.9 & 297.5 to 406.8 \\
\hline Group 2 & $117 / 1,087$ & -9.4 & 503.3 & 418.2 to 600.9 \\
\hline Group 3 & $54 / 1,306$ & -4.1 & 154.4 & 117.2 to 199.8 \\
\hline Group 4 & $139 / 4,369$ & -3.2 & 123.2 & 104.0 to 145.0 \\
\hline Group 5 & $36 / 2,405$ & -1.5 & 54.4 & 38.7 to 74.4 \\
\hline $\begin{array}{l}\text { Group } \\
\text { other }\end{array}$ & $226 / 10,793(2.1)$ & 74.9 & $65.6-85.1$ & \\
\hline
\end{tabular}

$\begin{array}{lllll}\text { All groups } & 729 / 21,982 & -3.4 & 124.8 & 115.8 \text { to } 133.9\end{array}$

Group 1 was defined as patients with conotruncal defects, including common arterial trunk, transposition of the great arteries, tetralogy of Fallot or aortopulmonary septum defect. Group 2 was defined as patients with nonconotruncal defects, including endocardial cushion defects, common ventricle and hypoplastic left heart syndrome. Group 3 was defined as patients with coarctation of the aorta. Group 4 was defined as patients with ventricular septal defects. Group 5 was defined as patients with atrial septal defects. Group other included all other heart and circulatory system anomalies and all other CHD diagnosis that were not included in the other five lesion groups.

${ }^{*}$ Mean IR in controls $1.2 / 10^{5}$ years.

$\mathrm{CHD}$, congenital heart disease; $\mathrm{HF}$, heart failure; IR, incidence rate, new cases per 100; patient years. six patients who underwent heart-lung transplantation. Of the 729 patients with CHD and HF, 17 were heart transplanted with a mean age of 12.5 years and a mean transplant-free survival of 19.1 years.

Estimates of cumulative incidence of $\mathrm{HF}$ with death as a competing event in patients with CHD and controls are presented in figure 1 . In patients with $\mathrm{CHD}$, the cumulative incidence of death and HF until the age of 42 years reached $9.5 \%$ and $6.5 \%$, respectively. In patients with CHD, the HF incidence was highest in infancy, approaching zero between 1 and 25 years of age, after which there was a gradual increase.

Figure 2 depicts the estimated cumulative incidence of HF across CHD lesion groups, compared with their matched controls. Cumulative risk of HF by 42 years was $6.5 \%(95 \%$ CI 5.8 to 7.2$)$ in all CHD and $14.8 \%(95 \%$ CI 12.1 to 17.4) in complex CHD (lesion groups 1 and 2). Online supplementary figure 1 shows the cumulative incidence of HF in women and men, which was comparable, reaching $6 \%$ and $7 \%$, respectively, by 42 years of age.

Diabetes, atrial fibrillation, stroke, hypertension and ischaemic heart disease are well-established risk factors for development of HF. The risk factors in the study population up to the time of HF diagnosis are presented in table 4. Patients with CHD had considerably lower prevalence of these additional risk factors compared with the controls, $19.9 \%(145 / 729)$ versus $53.3 \%$ (40/75), respectively.

An estimate of the cumulative probability of death in patients with CHD and controls after HF diagnosis as compared with those without $\mathrm{HF}$ is shown in figure 3. The mortality in patients with CHD and HF was $63.4 \%$ (95\% CI 57.5 to 69.3 ) at 42 years of follow-up, compared with $11.4 \%$ (95\% CI 10.5 to 12.3 ) for all other CHD cases. Notably, among the 75 controls who experienced HF, there were five deaths and an estimated mortality rate of $37.3 \%$ at 42 years of follow-up, although with very wide CIs (95\% CI 8.7 to 65.9$)$. The median time from HF diagnosis in patients with CHD and controls to death was 25.8 (10.8-26.2) and 3.1 (2.2-3.9) years, respectively.

\section{DISCUSSION}

The present study is the first nation-wide study in Sweden on the development of HF in young patients with CHD, compared with matched controls. In this cohort, followed up to 42 years of age, the risk of developing HF for patients with CHD increased more than 100-fold, compared with matched controls during a mean follow-up period of 27 years. However, the absolute risk in patients with CHD to develop HF is low (2\%); $3.3 \%$ of patients with CHD had a diagnosis of $\mathrm{HF}$ compared with $0.03 \%$ of controls.

\section{Incidence of $\mathrm{HF}$ in CHD}

The risk of developing HF in patients with CHD compared with controls significantly increased in all birth decade cohorts, but the highest risk was in the cohort born in 


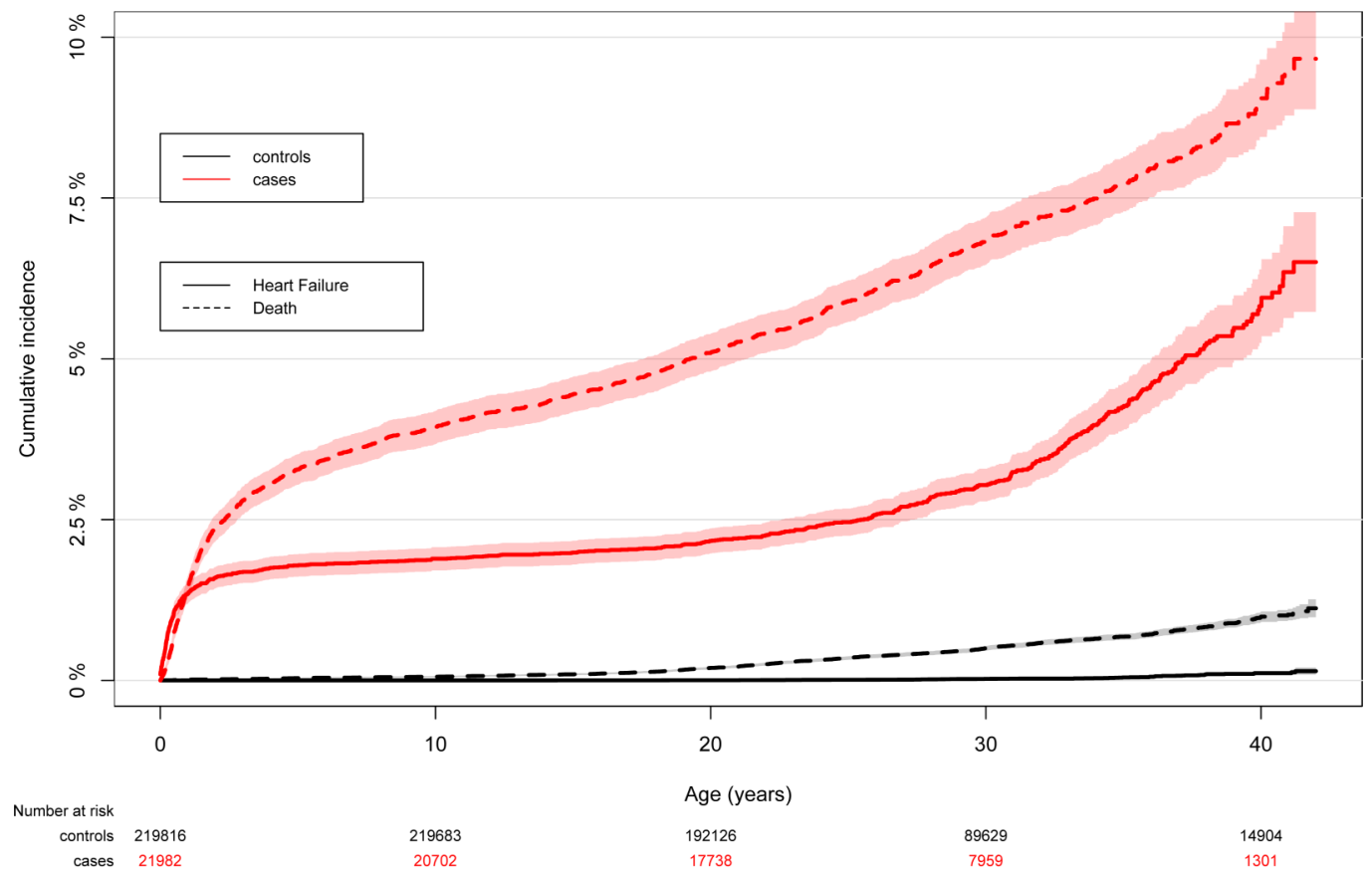

Figure 1 Cumulative incidence of $\mathrm{HF}$ in the study population, with death as a competing event. Solid black line indicates $\mathrm{HF}$ among controls, dashed black line indicates death among controls, solid red line indicates HF among patients with CHD and dashed red line indicates death among patients with CHD. CHD, congenital heart disease; HF, heart failure.

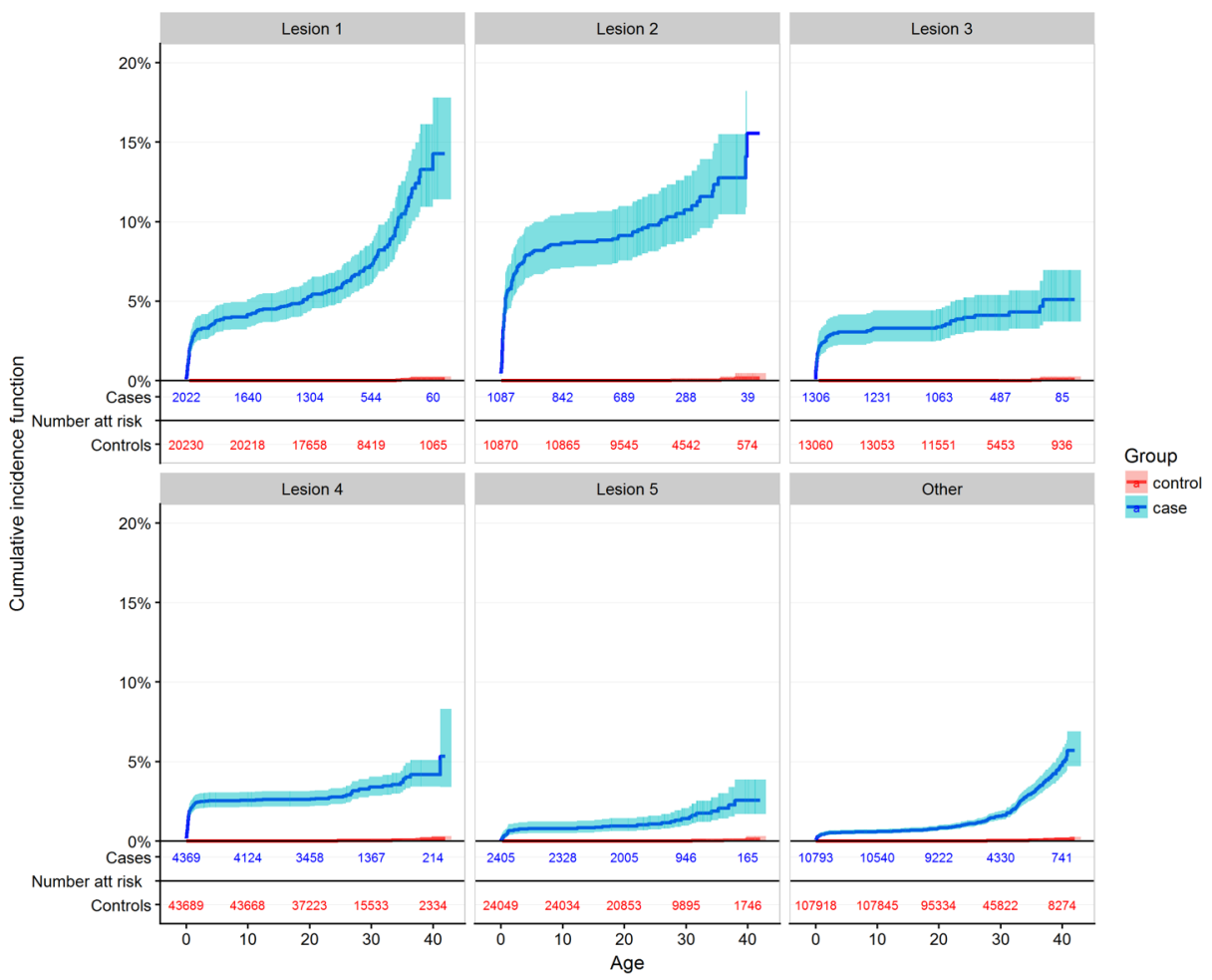

Figure 2 Cumulative incidence of heart failure in patients with $\mathrm{CHD}$ and controls according to a hierarchical classification. Lesion group 1 was defined as patients with conotruncal defects, including common arterial trunk, transposition of the great arteries, tetralogy of Fallot or aortopulmonary septum defect. Lesion group 2 was defined as patients with nonconotruncal defects, including endocardial cushion defects, common ventricle and hypoplastic left heart syndrome. Lesion group 3 was defined as patients with coarctation of the aorta. Lesion group 4 was defined as patients with ventricular septal defects. Lesion group 5 was defined as patients with atrial septal defects. Lesion group other included all other heart and circulatory system anomalies and all other CHD diagnoses that were not included in the other five lesion groups. CHD, congenital heart disease. 
Table 4 Risk factors for development of HF prior to or at the time of HF diagnosis in the study population

\begin{tabular}{lc}
$\begin{array}{l}\text { Patients with } \\
\text { congenital heart } \\
\text { disease and HF, } \\
\mathbf{n = 7 2 9}\end{array}$ & $\begin{array}{l}\text { controls } \\
\text { with HF, }\end{array}$ \\
\hline $6(0.8)$ & $3(4.0)$ \\
$70(9.6)$ & $9(12.0)$ \\
$12(1.6)$ & $2(2.7)$ \\
$24(3.3)$ & $13(17.3)$ \\
$33(4.5)$ & $13(17.3)$
\end{tabular}

HF, heart failure.

the 1980 s. In the 1970 s cohort, there were fewer patients registered than that of the 1980 s, which could imply that a substantial portion of the 1970 s cohort may not have been registered. In the 1990 s cohort, the CI for the HR was considerable. The difference in HR between birth cohorts should therefore be interpreted with caution. Nevertheless, the higher risk of $\mathrm{HF}$, as well as the cumulative incidence of HF in the 1980s cohort, may in part be because of improved survival compared with the $1970 \mathrm{~s}$ cohort, most notably among patients with complex CHD, as previously reported with these patients. ${ }^{11}$

The estimated cumulative incidence of $\mathrm{HF}$ by 42 years of age was high, reaching $6.5 \%$ in the entire cohort and $14.8 \%$ in the complex lesion groups 1 and 2 . The population-based incidence of HF from birth in patients with CHD compared with the general population has not been reported. A recent study from Taiwan documented major cardiovascular adverse events in a national cohort of 3267 adult patients with CHD, which were compared with 6534 matched controls. This study found that the HR for HF was between 11 and 21 in patients with CHD during a follow-up of 4 years. ${ }^{18}$ Because the cohort was not followed from birth and one-third of the cohort entered the study when they were over 40 years of age, the lifetime risk for $\mathrm{HF}$ may have been significantly underestimated.

According to our findings, the cumulative incidence of HF was similar in both men and women with CHD up to 42 years of age, which contradicts previous theories about sex differences in patients with CHD. ${ }^{19}$

The incidence of $\mathrm{HF}$ in the adult $\mathrm{CHD}$ population has recently come into focus. A registry study from the Netherlands of 10808 patients with CHD reported a cumulative risk of hospital admissions for $\mathrm{HF}$ of $1 \%$ at 40 years of age and $6 \%$ at 60 years, ${ }^{6}$ which is lower than the cumulative incidence of HF in patients with $\mathrm{CHD}$ of $6.5 \%$ at 42 years in our study. The corresponding HF incidence among 274 admitted patients with CHD, with a median age of 47 years in the Dutch study was 120 per $10^{5}$ patient years, which is comparable to the overall HF incidence of 125 per $10^{5}$ patient years in the present study.

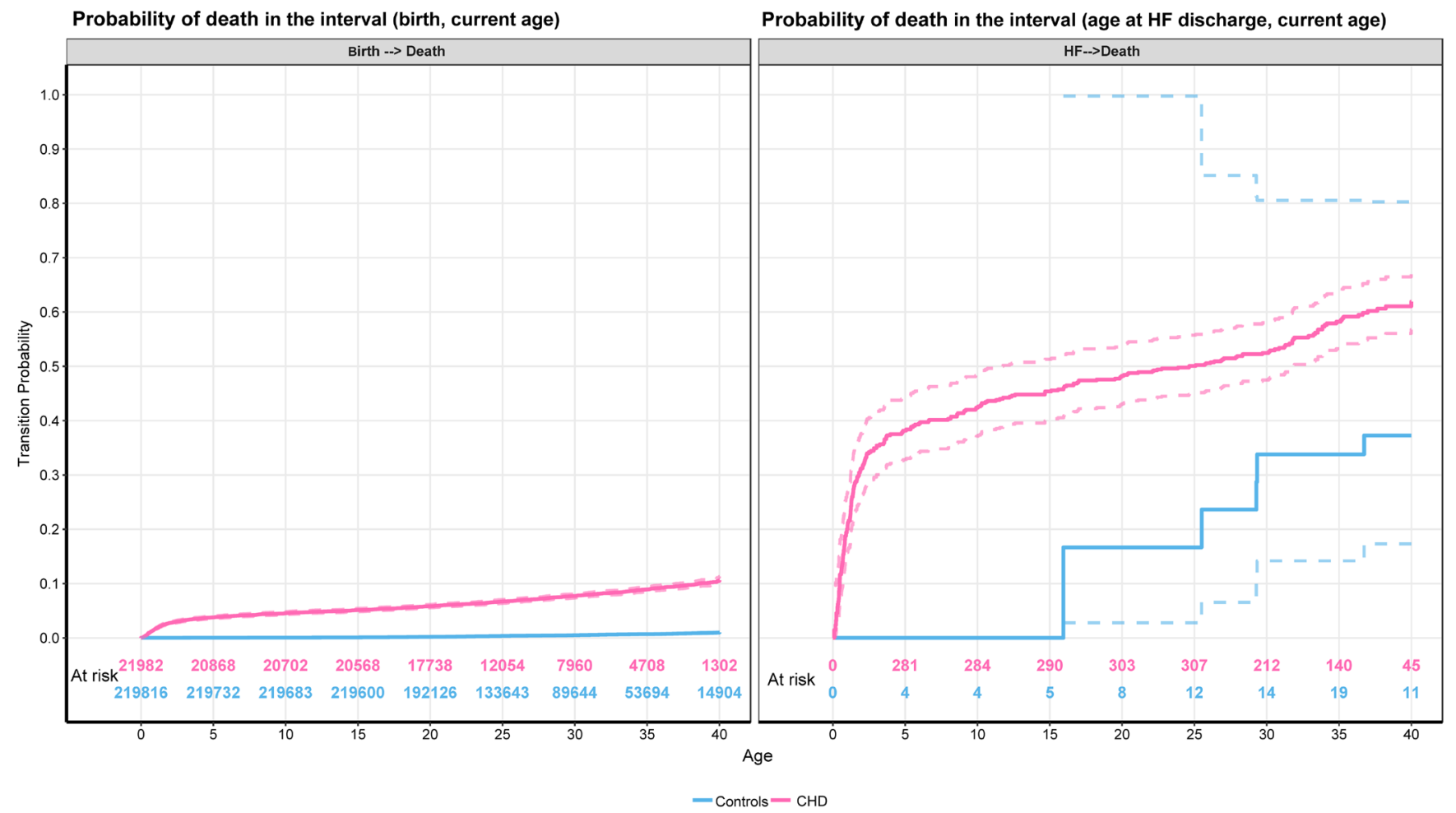

Figure 3 Mortality $(95 \% \mathrm{Cl})$ in patients and controls with HF (right panel), compared with those without HF (left panel). Red lines indicate patients with congenital heart disease, blue lines represent controls and dashed lines indicate $95 \% \mathrm{Cls}$. HF, heart failure. 


\section{Diagnosis-specific spectrum of $\mathrm{HF}$ in CHD}

In our study, the incidence for HF in patients with the most complex CHD was $>300$ times higher than that of controls. Up to $14.8 \%$ of patients with complex CHD were predicted to develop HF by 42 years of age. Furthermore, the HF incidence rate in simple CHD (lesion groups 3-5), comprising coarctation of the aorta, ventricular septal and atrial septal defects, was 54-123 times that of controls, with a predicted HF rate of approximately $5 \%$ by 42 years of age.

There are few population-based data on the diagnosis-specific spectrum of HF in patients with CHD. Results from our study, as well as from the previous studies, have shown that patients with complex CHD, such as univentricular heart, transposition of the great arteries (with a systemic right ventricle) and tetralogy of Fallot, have the highest risk of developing $\mathrm{HF}^{6}{ }^{620}$ This emphasises the role of the right ventricle in HF among patients with CHD, as opposed to predominantly left ventricular failure in patients with acquired heart disease. ${ }^{21}{ }^{22}$ Nevertheless, in a recent US nation-wide study of 84000 hospitalisations in adult patients with CHD, of which $20 \%$ were because of $\mathrm{HF}, 52 \%$ of HF patients were $>65$ years. The most common diagnoses were atrial septal defects (44\%), aortic valve disease $(13 \%)$ and ventricular septal defects $(9 \%){ }^{8}$ The high prevalence of comorbidities included arrhythmia (52\%), hypertension (52\%), diabetes (25\%) and renal failure (19\%). This illustrates that, although patients with complex lesions have a high risk of developing HF early in life, in the future a substantial portion of older patients with CHD with HF may consist of those with simple lesions, where HF may be precipitated by traditional and modifiable risk factors. ${ }^{23}$

\section{Prognosis of $\mathrm{HF}$ in CHD}

The present study establishes that HF diagnosis is associated with high mortality in patients with CHD. The probability of death by 42 years of age increased from $11 \%$ to $63 \%$ in the presence of a HF diagnosis. These data on high mortality among patients with CHD with HF are supported by a registry report from the Netherlands on 3-year mortality after hospital admission for $\mathrm{HF}$, at a median age of 46.7 years, of approximately $25 \%$ in women and $40 \%$ in men. ${ }^{6}$ Their finding of a substantial sex difference was not reproduced in our data (data not shown). Similar single-institution data after hospital admission in $4.6 \%$ of a cohort of 3862 patients with a mean age of 58 years were recently published in which the 5 -year mortality was $45 \% .^{24}$ When admitted for HF, patients with CHD have been reported to have a more than three times risk of death compared with patients with non-CHD. ${ }^{825}$

Furthermore, a recent German registry study identified progressive $\mathrm{HF}$ as a leading cause of death in patients with CHD, occurring in $28 \%$ of all deaths with a relative over-representation of the abovementioned diagnoses with a high risk of HF: univentricular heart, transposition of the great arteries and Eisenmenger's syndrome. ${ }^{9}$

\section{Future perspectives}

We have estimated a HF prevalence of $6.5 \%$ at 42 years in this Swedish population with CHD. As the population with CHD ages, acquired heart diseases will become increasingly common, ${ }^{26}$ and so will traditional cardiovascular risk factors such as hypertension, hyperlipidaemia and renal failure. For example, a Belgian study of 1976 adult patients with CHD documented at least one cardiovascular risk factor in almost $80 \%$ of patients. ${ }^{26}$ Furthermore, recently published case-control data in the same cohort as this study have documented a high hazard rate of ischaemic heart disease and atrial fibrillation, both of which can precipitate $\mathrm{HF}^{27}{ }^{28}$ In contrast, changing surgical strategies, such as the shift from atrial redirection to arterial switch in patients with transposition, will reduce the number of patients with a morphological right ventricle functioning as the systemic ventricle.

\section{Limitations of the study}

The study was based on registers, without access to clinical data. For confidentiality reasons, we could only use coded data and we were consequently unable to validate the diagnoses through hospital records. In Sweden, patients with CHD are generally diagnosed and treated at specialist centres, which should minimise misclassification, although occasional errors because of alteration in ICD 8th, 9th and 10th versions cannot be ruled out. Diagnosis of HF is difficult, in particular for patients with complex, underlying cardiac diagnosis. Nevertheless, external validations of the diagnoses of the Inpatient Register, including the HF diagnosis, have been shown to have a high validity of $85 \%-95 \%{ }^{1729}$ Finally, the Outpatient Register started in 2000; therefore, occasional patients who were only managed in outpatient clinics before 2000 could not be identified.

In conclusion, the risk of $\mathrm{HF}$ in children and young adult patients with CHD was more than 100 times higher compared with that of matched controls. At the age of 42 years, $6.5 \%$ of patients with CHD were predicted to develop HF, reaching $14.8 \%$ in complex cases. Caring for patients with complex congenital conditions who develop HF may demand significant attention from the adult CHD cardiologist in the future. Attention to modifiable risk factors is therefore important, and increased surveillance may be warranted as patients with CHD approach the age when HF prevalence increases in the general population.

Contributors Both TG and ZM contributed equally to this manuscript.

Funding This work was supported by grants from the Swedish state (under the agreement between the Swedish government and the county councils concerning economic support of research and education of doctors, ALF-agreement), grants from the Sahlgrenska Academy, the Swedish Heart and Lung Foundation (grant number 2015-0438), the King Gustaf V's and Queen Victoria's Freemasons Foundation, the Swedish Research Council (grant numbers 2013-5187, 2013-4236), and the Swedish Council for Health, Working Life and Welfare (FORTE).

Competing interests None declared.

Patient consent for publication Not required.

Provenance and peer review Not commissioned; externally peer reviewed. 
Data sharing statement No additional data are available.

Open access This is an open access article distributed in accordance with the Creative Commons Attribution Non Commercial (CC BY-NC 4.0) license, which permits others to distribute, remix, adapt, build upon this work non-commercially, and license their derivative works on different terms, provided the original work is properly cited, appropriate credit is given, any changes made indicated, and the use is non-commercial. See: http://creativecommons.org/licenses/by-nc/4.0/.

\section{REFERENCES}

1. Marelli AJ, Mackie AS, lonescu-Ittu R, et al. Congenital heart disease in the general population: changing prevalence and age distribution. Circulation 2007:115:163-72.

2. Moons P, Bovijn L, Budts W, et al. Temporal trends in survival to adulthood among patients born with congenital heart disease from 1970 to 1992 in Belgium. Circulation 2010;122:2264-72.

3. Marelli AJ, lonescu-Ittu R, Mackie AS, et al. Lifetime prevalence of congenital heart disease in the general population from 2000 to 2010. Circulation 2014;130:749-56.

4. Gilboa SM, Devine OJ, Kucik JE, et al. Congenital heart defects in the United States: estimating the magnitude of the affected population in 2010. Circulation 2016;134:101-9.

5. Zomer AC, Vaartjes I, Uiterwaal CSPM, et al. Circumstances of death in adult congenital heart disease. Int J Cardiol 2012;154:168-72.

6. Zomer AC, Vaartjes I, van der Velde ET, et al. Heart failure admissions in adults with congenital heart disease; risk factors and prognosis. Int J Cardiol 2013;168:2487-93.

7. Verheugt CL, Uiterwaal CSPM, van der Velde ET, et al. Mortality in adult congenital heart disease. Eur Heart J 2010;31:1220-9.

8. Rodriguez FH, Moodie DS, Parekh DR, et al. Outcomes of heart failure-related hospitalization in adults with congenital heart disease in the United States. Congenit Heart Dis 2013;8:513-9.

9. Engelings $\mathrm{CC}$, Helm PC, Abdul-Khaliq $\mathrm{H}$, et al. Cause of death in adults with congenital heart disease - An analysis of the German National Register for Congenital Heart Defects. Int J Cardiol 2016;211:31-6.

10. Mandalenakis Z, Rosengren A, Lappas G, et al. Ischemic stroke in children and young adults with congenital heart disease. J Am Heart Assoc 2016;5. doi:10.1161/JAHA.115.003071. [Epub ahead of print: 23 Feb 2016].

11. Mandalenakis Z, Rosengren A, Skoglund K, et al. Survivorship in children and young adults with congenital heart disease in Sweden. JAMA Intern Med 2017;177:224-30.

12. Sjätte upplagen. Classification of operations, Swedish version, 6th edition, 1993 (Socialstyrelsen.Klassifikation AV operationer), 1993. Available: http://www.socialstyrelsen.se/klassificeringochkoder/ Documents/Op6.pdf [Accessed 14 Jun 2017].
13. Socialstyrelsen. Classification of surgical procedures, version 1.9, Swedish version 1997 (351 klassifikation AV kirurgiska åtgärder: 1997), 1997. Available: http://www.socialstyrelsen.se/Lists/ Artikelkatalog/Attachments/10244/2004-41_200441.pdf [Accessed 14 Jun 2017]

14. Botto LD, Lin AE, Riehle-Colarusso T, et al. Seeking causes: classifying and evaluating congenital heart defects in etiologic studies. Birth Defects Res A Clin Mol Teratol 2007;79:714-27.

15. Oyen N, Poulsen G, Boyd HA, et al. National time trends in congenital heart defects, Denmark, 1977-2005. Am Heart J 2009;157:467-73.

16. Liu S, Joseph KS, Luo W, et al. Effect of folic acid food fortification in Canada on congenital heart disease subtypes. Circulation 2016;134:647-55.

17. Ingelsson E, Arnlöv J, Sundström J, et al. The validity of a diagnosis of heart failure in a hospital discharge register. Eur $J$ Heart Fail 2005;7:787-91.

18. Lin Y-S, Liu P-H, Wu L-S, et al. Major adverse cardiovascular events in adult congenital heart disease: a population-based follow-up study from Taiwan. BMC Cardiovasc Disord 2014;14.

19. Engelfriet $P$, Mulder BJM. Gender differences in adult congenital heart disease. Neth Heart J 2009;17:414-7.

20. Norozi K, Wessel A, Alpers V, et al. Incidence and risk distribution of heart failure in adolescents and adults with congenital heart disease after cardiac surgery. Am J Cardiol 2006;97:1238-43.

21. Zomer AC, Vaartjes I, Grobbee DE, et al. Adult congenital heart disease: new challenges. Int J Cardiol 2013;163:105-7.

22. Warnes CA. Adult congenital heart disease importance of the right ventricle. J Am Coll Cardiol 2009;54:1903-10.

23. Tutarel $O$. Acquired heart conditions in adults with congenital heart disease: a growing problem. Heart 2014;100:1317-21.

24. Lal S, Kotchetkova I, Cao J, et al. Heart failure admissions and poor subsequent outcomes in adults with congenital heart disease. Eur J Heart Fail 2018;20:812-5.

25. Krieger EV, Valente AM. Heart failure treatment in adults with congenital heart disease: where do we stand in 2014? Heart 2014;100:1329-34.

26. Moons P, Van Deyk K, Dedroog D, et al. Prevalence of cardiovascula risk factors in adults with congenital heart disease. Eur J Cardiovasc Prev Rehabil 2006;13:612-6.

27. Fedchenko M, Mandalenakis Z, Rosengren A, et al. Ischemic heart disease in children and young adults with congenital heart disease in Sweden. Int J Cardiol 2017;248:143-8.

28. Mandalenakis Z, Rosengren A, Lappas G, et al. Atrial fibrillation burden in young patients with congenital heart disease. Circulation 2018;137:928-37.

29. Ludvigsson JF, Andersson E, Ekbom A, et al. External review and validation of the Swedish national inpatient register. BMC Public Health 2011;11. 